\title{
A Revisit to the Impacts of Land Use Changes on the Human Wellbeing via Altering the Ecosystem Provisioning Services
}

\author{
Xiangzheng Deng, ${ }^{1,2}$ Zhihui Li, $^{1,2,3}$ Jikun Huang, ${ }^{1,2}$ Qingling Shi, ${ }^{1,2}$ and Yanfei Li ${ }^{4}$ \\ ${ }^{1}$ Institute of Geographic Sciences and Natural Resources Research, Chinese Academy of Sciences, Beijing 100101, China \\ ${ }^{2}$ Center for Chinese Agricultural Policy, Chinese Academy of Sciences, Beijing 100101, China \\ ${ }^{3}$ University of Chinese Academy of Sciences, Beijing 100049, China \\ ${ }^{4}$ Faculty of Resources and Environmental Science, Hubei University, Wuhan, Hubei 430062, China
}

Correspondence should be addressed to Xiangzheng Deng; dengxz.ccap@gmail.com

Received 22 August 2013; Accepted 6 November 2013

Academic Editor: Burak Güneralp

Copyright (C) 2013 Xiangzheng Deng et al. This is an open access article distributed under the Creative Commons Attribution License, which permits unrestricted use, distribution, and reproduction in any medium, provided the original work is properly cited.

\begin{abstract}
It is widely acknowledged that land use changes (LUC) associated with climate variations are affecting the human wellbeing. This paper conducted a revisit to relevant researches on the impacts of LUC on human wellbeing via specifically altering the ecosystem provisioning services. First, the explorations on the influences of LUC on ecosystem provisioning services were reviewed, including the researches on the influences of LUC on agroecosystem services and forest and/or grassland ecosystem services. Then the quantitative identification of the impacts of LUC on ecosystem provisioning services was commented on. In the light of enhanced observation and valuation methods, several approaches to ecosystem services and improved models for assessing those ecosystem services were assessed. The major indicators used to uncover the influences of LUC on human wellbeing were summarized including the increase of inputs and the reduction of outputs in production and the augmented health risk induced by the irrational land uses. Finally, this paper uncovered the research gaps and proposed several research directions to address these gaps.
\end{abstract}

\section{Introduction}

The relationship between human activities and ecosystems has been discussed for many years by both natural and social scientists. LUC and climate variations and their effects on ecosystems have been core issues of the International Geosphere-Biosphere Program (IGBP) and International Human Dimensions Program on Global Environmental Change (IHDP). As two interacting processes, LUC and climate variations influence each other. On one hand, climate variations affect human activities, which indirectly exert influences on LUC, and on the other hand, LUC caused by humans accelerate influences on climate variations. Meanwhile, all these changes exert impacts on ecosystems together. In recent years, ecosystem services have been considered as an entry point of science to uncover the human and nature coevolution processes. Ecosystem services represent the benefits that living organisms derived from ecosystems to maintain the earth's life support system and emphasize the role of humans in socioecological systems, which include supporting services, regulating services, provisioning services, and cultural services [1]. As the global population grows and its consumption patterns change, additional land will be required for living space and agricultural production. Then the knotty question facing global society is how to meet humans' growing demands for living space, food, fuel, and other materials while sustaining ecosystem services and biodiversity under LUC and climate variations. Numerous studies have shown that LUC and climate variations affected the structure and function of ecosystems and then affected the supply of ecosystem services [2-4]. LUC might increase the provision and value of some services but decrease others [5]. Land use decisions that intend to maximize a single outcome such as agricultural production or timber production are likely to generate an accompanying decline in the provision of other services [1]. 
It is well known that ecosystems provide necessary services for the livelihoods and human wellbeing through various ecosystem services, which directly or indirectly sustain the quality of human life. While LUC and climate variations have effects on those various ecosystem services in space and time, which are mainly presented through agroecosystem and forest and/or grassland ecosystems. As to agroecosystem services, it would definitely be weakened if the cultivated land was degenerated and the climate variations were intensified remarkably, which would result in the loss of food production. It is the same to the forest ecosystem services and the grassland ecosystem services. Nowadays there is considerable uncertainty about the values of ecosystem services, which are of great importance to be identified $[6,7]$.

Ecosystems play an important role in providing goods through provisioning services, which is the most apparent connection between ecosystem services and human wellbeing [8]. Provisioning services are manifested in the goods people obtain from ecosystems such as food and fiber, fuel in the form of peat, wood or nonwoody biomass, and water from rivers, lakes, and aquifers. These goods may be provided by heavily managed ecosystems, such as agroecosystem and plantation forests. Thus, provisioning services are the focus of human activities. When humans derive overmuch provisioning services from nature, it will put both ecosystems and humans at risk. The effects of LUC and climate variations may increase changes in ecosystem services delivery [9]. As to the impacts of climate variations on human wellbeing, it can aggravate the situation for food security by increasing risks of crop failure because of the higher frequency of extreme events and progressive changes of climate [10]. In addition, as some ecosystem services decline, some new human actions, such as the excessive use of fertilizers and pesticides, have had adverse impacts on ecosystems and further on human wellbeing [11]. Studies on the impacts of LUC and climate variations on ecosystem provisioning services and the impacts of provisioning services changes on human wellbeing will provide scientific and theoretical basis for global policy making.

Comprehensive understanding and acknowledgements of main research progress about the relationship between human activities and ecosystems and the influence on human wellbeing via altering the ecosystem services are of great significance to guide future studies and further policy making. Thus this paper integrated previous studies to conduct a revisit to the impacts of LUC and climate variations on the human wellbeing via altering the ecosystem provisioning services (Figure 1). In this paper, Section 2 reviewed the exploration on the functions of LUC and climate variations on ecosystem provisioning services. Climate variations related to ecosystem services can be expressed by changes in temperature, precipitation, heat flux and some abnormal climate, and so forth. LUC related to ecosystem services include cultivated land reclamation, afforestation and deforestation, grassland degeneration, and built-up land expansion. The changes of them would have impacts on ecosystem services, including regulating services, provisioning services, supporting services, and cultural services. In addition, the altering of the provisioning services of agroecosystem and forest and/or grassland ecosystems was explored and commented on. In Section 3, the quantitative identifications of LUC and climate variations impacts on ecosystem services were reviewed. The enhanced observation and valuation approaches of ecosystem services and improved models for assessing ecosystem services were illustrated. In Section 4, the major indicators used to uncover the influences of ecosystem services changes on human wellbeing were revisited via the increased inputs with reduced outputs in production and the augmented health risk induced by the irrational land uses. As to Section 5, some research gaps were identified; the research needs and research prospects in further studies were also refined.

\section{Exploration on the Functions of LUC on Ecosystem Provisioning Services}

The ecosystems can provide a variety of direct and indirect services to humans and other living organisms, and those services can be affected by climate variations and human activities, especially human-induced LUC [12-14]. Some studies have shown that LUC and climate variations are amongst the greatest global environmental pressures resulting from anthropogenic activities, which significantly influence the provision of crucial ecosystem services, such as carbon sequestration, water flow regulation, and food and fiber production, at a variety of scales [15]. In the researches of the relationship between LUC and ecosystem services, the analyses of the impacts of LUC on ecosystem services were usually conducted from the aspect of land use quantity and structure changes. Some studies have indicated that the diversification of land use would help to improve ecosystem services $[16,17]$. In addition, combined effects of LUC and climate variations may change ecosystem services, especially the food provision and water yield of agroecosystem, forest and/or grassland ecosystems [18, 19].

2.1. Influences of LUC on the Agroecosystem Services. As a kind of specific complex manual-natural ecosystem, agroecosystem not only has efficient and direct production function, but also the function of environmental services, tourism services, and aesthetic services [20]. Agriculture is a dominant form of land management globally, and agroecosystem covers nearly $40 \%$ of the terrestrial surface of the earth [11]. Agroecosystem is faced with severe challenges under the context of global warming and the intensive human-induced LUC.

More and more current studies have shown that LUC especially rapid urbanization has already directly or indirectly affected the food provisioning services of agroecosystem $[21,22]$. The quality and quantity changes of agricultural land have potential effects on provision services of agroecosystem. However, some studies have shown that agricultural land use has degraded the soil, water, NPP, and the biological assets in agroecosystem to such an extent that the restoration of natural capital and rehabilitation of ecosystem services are needed through changes in land use and management [23]. A primary reason for this degradation is the failure of agricultural commodity markets to internalize 


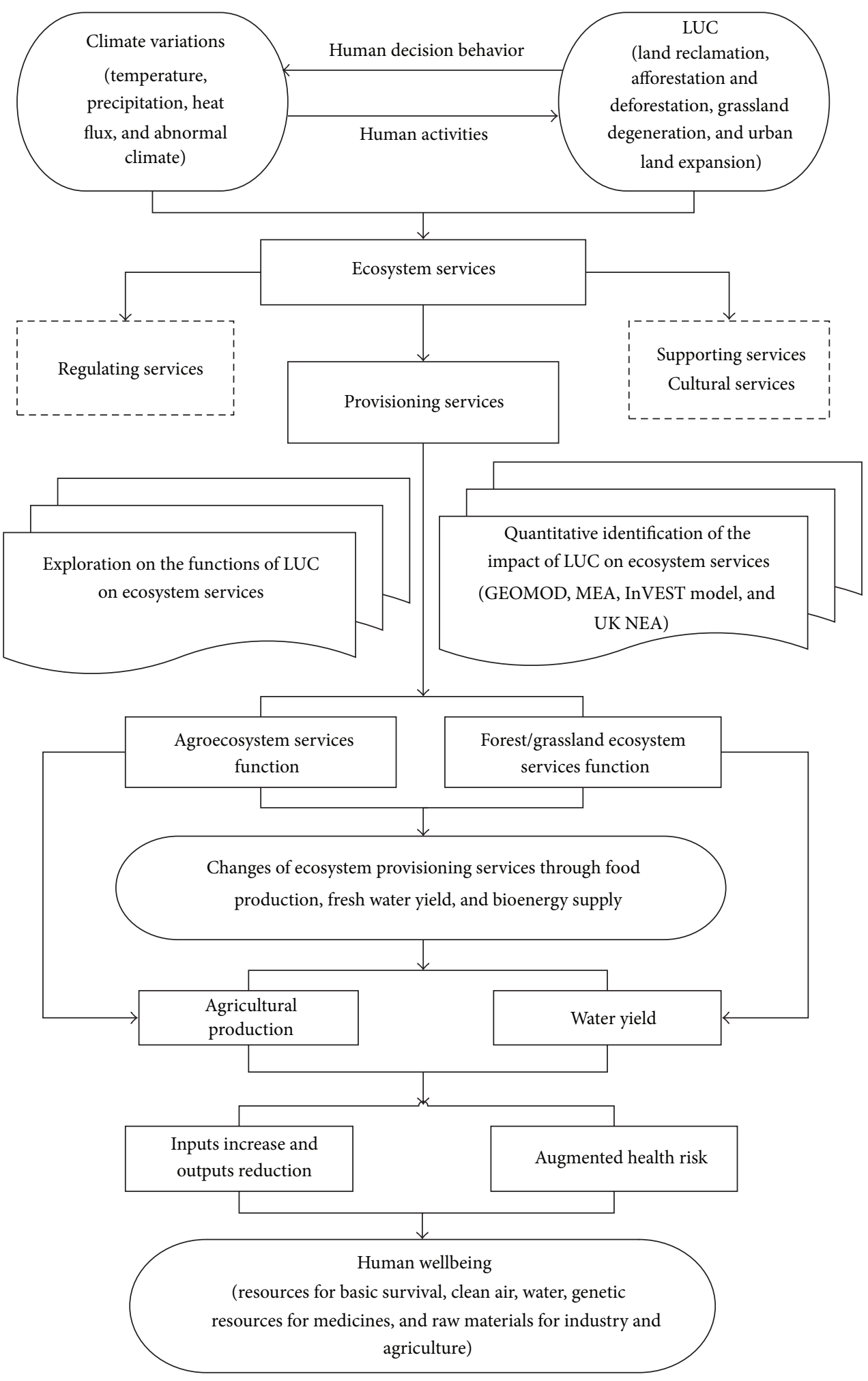

FIGURE 1: Diagram to trace the impacts of LUC and climate variations on the human wellbeing via altering the ecosystem provisioning services. 
environmental costs associated with land use and management decisions.

The LUC especially the excessive reclamation of cropland and the intensive agriculture land use exert potential effects on biodiversity conservation of agroecosystem, which will influence the stability of provisioning services in agroecosystem. Some studies have indicated that the rapid expansion and intensification of row crop production have resulted in the loss of habitat and spatial heterogeneity in agroecosystem, which affects the ecosystem provisioning services [24]. Land use conversion from natural lands to croplands, grazing lands, and urban areas has been increased over time, resulted in reduced or modified biodiversity, altered functional processes, and diminished provision of ecosystem goods and services to society globally [25-27]. Some studies also indicated that the intensive agricultural development could change land use, which can further affect regional ecosystem services [28].

2.2. Influences of LUC on the Ecosystem Services from Forest and/or Grassland. Forest and grassland ecosystems are indispensable constituent parts of terrestrial ecosystems which play important roles in global climate variations. Climate variations affect the water yield of forest and/or grassland ecosystems via its direct influence on precipitation and evaporation process of atmosphere hydrologic cycle. LUC including converting grassland or shrub lands to plantations, afforestation and reforestation, are gaining attention globally and will alter many ecosystem processes, including water yield of forest and grassland ecosystems [18, 29-31]. Changes in the extent and composition of forest, grassland, wetland, and other ecosystems have large impacts on the biophysical conditions, which further affect the provision of ecosystem services, biodiversity conservation. The LUC influence the water yield of ecosystems through changing the transpiration, interception, and evaporation, all of which tend to increase when grassland or scrubland are replaced with forests. Transpiration rates are influenced by changes in rooting characteristics, leaf area, stomata response, plant surface albedo, and turbulence [32, 33].

Much progress has been made to understand the effect of LUC on water yield of forest ecosystems during the past century all over the world, the results of which generally indicated that LUC have both positive and negative effects on water yield. For example, clear-cutting forests in the US may result in the increase in annual water yield [34, 35]. The vegetation restoration will have positive effects on watershed health by reducing soil erosion and nonpoint source pollution, enhancing terrestrial and aquatic habitat, and increasing ecosystem carbon sequestration [19]. Some studies also indicated that vegetation changes, particularly those involving transitions between forests and grasslands dominated covers, often modify evaporative water losses as a result of plant-mediated shifts in moisture access and demand. And massive afforestation of native grassland have strong yet poorly quantified effects on the hydrological cycle [18]. Since forests with well-developed root systems cost plentiful ground water and soil water, it can save plenty of water to convert forest into short seasonal crops. To plant abundant pasture instead of forest in catchment areas is becoming a widely used method to increase water yield.

\section{Quantitative Identification of the Impacts of LUC on Ecosystem Services}

Many ecologists and natural scientists study ecosystem processes to understand ecosystem services across different landscapes via quantifying ecosystem services [36]. Quantification and valuation of services, if linked with payments or incentives, can enhance policies and regulations that properly reward decisions that yield public benefits. It is well known that ecosystems are essential to the existence of humans, while ecosystem services are typically not priced correctly at their value because of absence of markets for ecosystem goods and services and inadequate or nonexistent information about the value of goods and services [37]. There are many studies evaluating the impacts of LUC on ecosystem services in both developed and developing countries [38, 39]. To sum up the quantitative researches so far, we found that there are two kinds of methods to value the ecosystem services, namely, observations based on remote sensing and GIS technology and modeling approaches.

3.1. Enhanced Observation and Valuation Approaches of Ecosystem Services. The historical ecosystem services value could be reflected by remote sensing along with a GIS-based model (GEOMOD) since LUC are of the upper most driving forces of regional ecosystems and have huge impacts on ecosystem services value. Remote sensing provides reliable area-wide data for quantifying and mapping ecosystem services at comparatively low costs and with the fast, frequent, and continuous observations for monitoring. GEOMOD model is a kind of method and technique to allocate LUC spatially and to evaluate its impact on ecosystems simply and transparently.

The selection of indicators to be used in the analyses of potential impacts of LUC is the main challenge after obtaining the remote sensing data. The valuation of different ecosystem services and the spatial-temporal monitoring of their respective changes can provide useful indicators of the potential impacts of LUC. Generally speaking, as the ecosystem services values were different for each land use category [40], Costanza et al. (1997) first attempted to estimate the ecosystem services value coefficients [4], then many researches use the same approach in order to quantify and map the ecosystem services values at global or regional scales [41-43]. Although there are many potential conceptual and empirical problems and limitations to estimate the ecosystem services values $[44,45]$, the magnitude of the estimated ecosystem services values changes in the LUC is substantial. Thus, it may still be possible to draw general inferences about the effect of the perceived LUC on the estimated ecosystem services values.

3.2. Improved Models for Assessing Ecosystem Services. More and more ecosystem services values were assessed by models 
around the world in recent decades, and it seems to have become a trend to assess various ecosystem services with models. To avoid the weakness of common assessment models used before, some improved approaches or models were formed to assess the ecosystem services values, including the Millennium Ecosystem Assessment (MEA) approach [46], Integrated Valuation of Ecosystem Services and Tradeoffs (InVEST) [44] model, and the UK National Ecosystem Assessment [47].

The Millennium Ecosystem Assessment (MEA) was set up in 2000, it is the first time to provide a comprehensive picture of past, present, and possible future trends in ecosystem services and their values and propose corresponding measures. Many researchers have assessed the ecosystem services at national scale with framework of MEA. They have valued the agricultural ecosystem services, forest ecosystem services, and grassland ecosystem services in China [48]. For instance, 17 ecosystem services in 18 categories of grassland ecosystem in China have been assessed [49]. Exploring the researches between LUC and ecosystem services, we found that most studies analyzed the impacts by analyzing the quantity and structure change of land use. It is generally acknowledged that the provision of ecosystem services depends on biophysical conditions and changes over space and time due to humaninduced LUC. Spatial patterns of LUC can be linked to large regions and provide direct measures of human activities [50].

The InVEST model has been widely used in valuating ecosystem services values $[45,48,51]$. The model uses maps and tabular data of land use and land management in conjunction with environmental information, such as soil, topography, and climate, to generate spatially explicit predictions of the ecosystem services. InVEST model estimates the provision and value of ecosystem services under alternative land use scenarios. Economic information about demand for ecosystem services can be combined with biophysical supply to generate predictive maps of services use and values $[6,45]$. InVEST model also analyzes the impacts of land use and land management on species habitat provision and quality. Thus, the model provides a powerful tool for quantifying and valuing multiple ecosystem services and assessing the impacts of LUC. By varying land use or land management and evaluating the corresponding output with InVEST, we can provide useful information to managers and policy-makers to weigh the tradeoffs in ecosystem services, biodiversity conservation, and other land use objectives.

The UK National Ecosystem Assessment (UK NEA) is the first analysis of UK's natural environment in terms of the benefits it provides to society and the nation's continuing prosperity. It has been a wide-ranging, multistakeholder, cross-disciplinary process, designed to provide a comprehensive picture of past, present, and possible future trends in ecosystem services and their values; it is underpinned by the best available evidence and the most up-to-date conceptual thinking and analytical tools, which can be applied to assess the ecosystem services values aimed to describe the changes of key drivers that affect UK's ecosystems, including changes in land use and climate. The UK NEA distinguished between the ecosystem processes and intermediate ecosystem services and the final ecosystem services that directly deliver welfare gains and/or losses to people. This distinction is important to avoid double counting in the valuation of ecosystem services [52]. As the researches go on, the UK NEA would have a broad application prospect to assess the impacts of human activities on ecosystem services.

At any rate, ecosystem services play an important role in maintaining the balance of global ecosystems and improving human living environment. Quantifying and mapping those ecosystem services is necessary to periodically determine the response of ecosystem services to global change, such as LUC and climate variations. Those approaches and models, though being widely used to quantify and map the ecosystem services values around the world, still have potential to be improved in order to get more accurate assessment results. In addition, so far there is still no assessment system and method that has been commonly approved by researchers. Therefore, it is still a hot issue to study the assessment of ecosystem services values to clarify the relationship between LUC and ecosystem services.

\section{Major Indicators Used to Uncover the Influences of Ecosystem Provisioning Services on Human Wellbeing}

Ecosystem services are essential for the maintaining of human wellbeing and the links between ecosystem services and human wellbeing are complex, diverse, and complicated to assess properly with the consideration of different spatial and temporal scales [53]. Healthy ecosystems provide services that are the foundation for human wellbeing including the provision of resources for basic survival, such as clean air, water, and genetic resources for medicines, along with the provision of raw materials for industry and agriculture [54]. Thus, the degradation and loss of ecosystem services have negative effect on human wellbeing. On one hand, the degradation and loss of ecosystem provisioning services will increase the inputs in production to recover reduced outputs in the ecosystems. On the other hand, the degradation and loss of provisioning ecosystem services will increase the human health risk.

4.1. Increased Inputs with Reduced Outputs in Production. Ecosystems are changed by the LUC and climate variations, all of which may reduce or increase the supply of ecosystem services temporarily or permanently. Some evidences have shown that the climate variations and human activities especially LUC have changed agricultural and natural ecosystems more rapidly and extensively over the last 50 years [1]. The MA reported that 15 of the world's 24 ecosystem services are in decline, which have affected human wellbeing and threaten the survival of other species. The declining ability of the earth's systems to meet the needs of a growing population and sustain the life support systems of the planet is a very urgent and serious issue. Due to the impacts of climate variation and LUC on agroecosystem services, the outputs humans obtained in agricultural production will decrease, including the food production and water yield. Therefore, humans would input more production factors such as fertilizers and 
pesticides in the process of food production and invest more in search of more water resources to sustain the continual ecosystem provision of human wellbeing.

The development of novel chemicals and new technologies during the last century has supported the modern agricultural revolution, resulting in an increase in food production and harvest rates [55]. Some studies have indicated that the application of fertilizers (such as the nitrogen application) and pesticides in some regions increased rapidly to meet the demands for greater food production needs [56, 57]. The increasing use of these chemicals and technologies removed the constraint of nutrient limitation for crop growth, as well as competitive pests and weeds, resulting in increased outputs. However, on the other side, these increased outputs are at the cost of the reducing ecosystem services, especially the provisioning services. Thus, human wellbeing would be weakened. With the ecosystem services changing, governments have supplied subsidies and grants to adjust personal and business behavior.

\subsection{Augmented Health Risk Induced by the Irrational Land} Uses. Ecosystem services can support the fundamental need of human wellbeing in a variety of ways. The changes of ecosystem services would both directly and indirectly put the humans' health at risk through the insufficient provision of food and fresh water, inorganic chemicals and persistent organic chemical pollutants in food and water, and infectious disease caused by ecosystem services loss [58]. Besides, the indirect health risk was caused by the irrational land uses.

The insufficient accesses to the ecosystem provisioning services of food production and water yield are particularly important factors leading to the health risks in human wellbeing. Some studies have indicated that a lack of access to the ecosystem provisioning services of food causes far more than physical harm, it may put thousands of millions of people in mental and physical potential risks by reducing intelligent and physical growth, in some cases from the moment of human conception [59]. Undernutrition was recently assessed as an underlying cause of death each year worldwide, which is particularly common in sub-Saharan Africa and South Asia, especially in India [60]. Vegetation especially the grass and forest is important for the interception of water. Some studies have shown that about 1 billion people were affected by land degradation caused by soil erosion, waterlogging, or salinity of irrigated land.

Humans are also at risk due to inorganic chemicals and persistent organic chemical pollutants in food and water and the infectious disease caused by ecosystem services loss [58]. Some studies indicated that human actions, for example, releasing toxic chemicals into the environment or using pesticide and chemical fertilizer, will pollute the water and food, which can have adverse effects on various organ systems [61]. Some evidence indicated that some chemicals from pesticide and chemical fertilizer have increased the microbial contamination of drinking water, which has led to the infectious diseases accounting for approximately $6 \%$ of all deaths globally [58]. The pattern and extent of change in incidence of particular infectious disease depends on the particular ecosystems affected, such as type of LUC. Some studies showed that climate changes and some LUC, such as deforestation, might alter infectious disease patterns [62, 63]. There have been lots of studies to investigate the influence of the increased income and the health risk of human wellbeing, which will be helpful to profoundly understand the influence mechanism and extent of the degradation of ecosystem services on human wellbeing.

\section{Concluding Remarks}

Based on current researches about the effects of LUC and climate variations on ecosystem services, we mainly focus on ecosystem provisioning services and the influence of the changes in provisioning services on human wellbeing. Firstly, we explored the researches on identification and quantification of the impacts of LUC on ecosystem services values and later examined how the impact on ecosystem provisioning services affects human wellbeing through analyses of the increased inputs and the reduced outputs of agricultural production and the augmented health risk of humans.

So far, there are still some researches to be done to uncover the impacts of LUC and climate variations on human wellbeing via ecosystem provisioning services. First of all, the current researches are focused on the ecosystem services values but the mechanisms through which LUC and climate variations influence ecosystem services are still not well understood. However, this is of great significance to the sustainable development of human wellbeing. Secondly, there would be uncertainty involved when the remote sensing data were used for quantifying and mapping ecosystem services. Therefore, validating the reliability of the results obtained by using remote sensing in quantifying and mapping ecosystem services needs to be done in further researches. As to the impacts of ecosystem services changes on human wellbeing, more researches on quantification of these impacts need to be done to make the research more comprehensive.

It has been shown by research practice that the assessment of ecosystem services was useful to the setting of strategies and policies, with potentially far-reaching influence on human activities. Thus, further researches are needed to focus on the following three issues. First, there is a need to formulate a set of thorough and normative method to assess ecosystem services values and improve the accuracy of assessment results. Second, an in-depth process-based analysis of the relationship between human activities and ecosystem services function is needed. Third, there is an urgent need to promote the application of ecosystem services values in various aspects of production, livelihood, and government decision-making and eventually serve for human wellbeing.

\section{Conflict of Interests}

The authors declare that there is no conflict of interests regarding the publication of this paper. 


\section{Acknowledgments}

This research was supported by China National Natural Science Funds for Distinguished Young Scholar (Grant no. 71225005), National Key Program for Developing Basic Science in China (Grant no. 2012CB955700), and Key Projects in the National Science \& Technology Pillar Program (Grant no. 2013BAC03B03).

\section{References}

[1] W. V. Reid, H. A. Mooney, A. Cropper et al., "Ecosystems and human well-being: synthesis," Millennium Ecosystem Assessment, 2005.

[2] E. Nelson, H. Sander, P. Hawthorne et al., "Projecting global land-use change and its effect on ecosystem service provision and biodiversity with simple models," PLoS ONE, vol. 5, no. 12, Article ID e14327, 2010.

[3] B. L. Turner, D. Skole, S. Sanderson, G. Fischer, L. Fresco, and R. Leemans, "Land-use and land-cover change: science/research plan," Global Change Report, 1995.

[4] R. Costanza, R. D’Arge, R. de Groot et al., "The value of the world's ecosystem services and natural capital," Nature, vol. 387, no. 6630 , pp. 253-260, 1997.

[5] M. Antrop, "Changing patterns in the urbanized countryside of Western Europe," Landscape Ecology, vol. 15, no. 3, pp. 257-270, 2000.

[6] G. C. Daily, S. Polasky, J. Goldstein et al., "Ecosystem services in decision making: time to deliver," Frontiers in Ecology and the Environment, vol. 7, no. 1, pp. 21-28, 2009.

[7] N. H. Euliss Jr., L. M. Smith, S. Liu et al., "The need for simultaneous evaluation of ecosystem services and land use change," Environmental Science and Technology, vol. 44, no. 20, pp. 7761-7763, 2010.

[8] G. E. Jones, P. Cross, N. Foley et al., "Provisioning services," UK National Ecosystem Assessment Technical Report, UNEPWCMC, Cambridge, UK, 2011.

[9] J. Alcamo, D. Van Vuuren, W. Cramer et al., "Changes in ecosystem services and their drivers across the scenarios," in Ecosystems and Human Well-Being: Scenarios, vol. 2, pp. 297374, Island Press, Washington DC, USA, 2005.

[10] M. V. K. Sivakumar, H. P. Das, and O. Brunini, "Impacts of present and future climate variability and change on agriculture and forestry in the arid and semi-arid tropics," Climatic Change, vol. 70, no. 1-2, pp. 31-72, 2005.

[11] A. G. Power, "Ecosystem services and agriculture: tradeoffs and synergies," Philosophical Transactions of the Royal Society B, vol. 365, no. 1554, pp. 2959-2971, 2010.

[12] M. J. Metzger, M. D. A. Rounsevell, L. Acosta-Michlik, R. Leemans, and D. Schröter, "The vulnerability of ecosystem services to land use change," Agriculture, Ecosystems and Environment, vol. 114, no. 1, pp. 69-85, 2006.

[13] R. F. Bangash, A. Passuello, M. Sanchez-Canales et al., "Ecosystem services in Mediterranean river basin: climate change impact on water provisioning and erosion control," Science of the Total Environment, vol. 458, pp. 246-255, 2013.

[14] D. Schröter, W. Cramer, R. Leemans et al., "Ecology: ecosystem service supply and vulnerability to global change in Europe," Science, vol. 310, no. 5752, pp. 1333-1337, 2005.

[15] B. Reyers, P. J. O’Farrell, R. M. Cowling, B. N. Egoh, D. C. le Maitre, and J. H. J. Vlok, "Ecosystem services, land-cover change, and stakeholders: finding a sustainable foothold for a semiarid biodiversity hotspot," Ecology and Society, vol. 14, no. 1, article 38, 2009.

[16] M. J. Swift, A. N. Izac, and M. van Noordwijk, "Biodiversity and ecosystem services in agricultural landscapes-are we asking the right questions?" Agriculture, Ecosystems and Environment, vol. 104, no. 1, pp. 113-134, 2004.

[17] C. Folke, J. Colding, and F. Berkes, "Synthesis: building resilience and adaptive capacity in social-ecological systems," in Navigating Social-Ecological Systems: Building Resilience for Complexity and Change, pp. 352-387, 2003.

[18] M. D. Nosetto, E. G. Jobbágy, and J. M. Paruelo, "Land-use change and water losses: the case of grassland afforestation across a soil textural gradient in central Argentina," Global Change Biology, vol. 11, no. 7, pp. 1101-1117, 2005.

[19] G. Sun, G. Zhou, Z. Zhang, X. Wei, S. G. McNulty, and J. M. Vose, "Potential water yield reduction due to forestation across China," Journal of Hydrology, vol. 328, no. 3-4, pp. 548-558, 2006.

[20] S. M. Swinton, F. Lupi, G. P. Robertson, and S. K. Hamilton, "Ecosystem services and agriculture: cultivating agricultural ecosystems for diverse benefits," Ecological Economics, vol. 64, no. 2, pp. 245-252, 2007.

[21] A. A. Jaradat and G. Boody, "Modeling agroecosystem services under simulated climate and land-use changes," ISRN Ecology, vol. 2011, Article ID 568723, 17 pages, 2011.

[22] J. Chen, "Rapid urbanization in China: a real challenge to soil protection and food security," Catena, vol. 69, no. 1, pp. 1-15, 2007.

[23] J. A. Foley, N. Ramankutty, K. A. Brauman et al., "Solutions for a cultivated planet," Nature, vol. 478, no. 7369, pp. 337-342, 2011.

[24] G. I. Gavier-Pizarro, N. C. Calamari, J. J. Thompson et al., "Expansion and intensification of row crop agriculture in the Pampas and Espinal of Argentina can reduce ecosystem service provision by changing avian density," Agriculture, Ecosystems and Environment, vol. 154, pp. 44-55, 2012.

[25] R. S. de Groot, M. A. Wilson, and R. M. J. Boumans, "A typology for the classification, description and valuation of ecosystem functions, goods and services," Ecological Economics, vol. 41, no. 3, pp. 393-408, 2002.

[26] P. Balvanera, A. B. Pfisterer, N. Buchmann et al., "Quantifying the evidence for biodiversity effects on ecosystem functioning and services," Ecology Letters, vol. 9, no. 10, pp. 1146-1156, 2006.

[27] S. Díaz, S. Lavorel, S. McIntyre et al., "Plant trait responses to grazing-a global synthesis," Global Change Biology, vol. 13, no. 2, pp. 313-341, 2007.

[28] V. H. Dale and S. Polasky, "Measures of the effects of agricultural practices on ecosystem services," Ecological Economics, vol. 64, no. 2, pp. 286-296, 2007.

[29] A. R. Nik, "Water yield changes after forest conversion to agricultural landuse in Peninsular Malaysia," Journal of Tropical Forest Science, vol. 1, no. 1, pp. 67-82, 1988.

[30] K. A. Farley, E. G. Jobbágy, and R. B. Jackson, "Effects of afforestation on water yield: a global synthesis with implications for policy," Global Change Biology, vol. 11, no. 10, pp. 1565-1576, 2005.

[31] V. Sahin and M. J. Hall, "The effects of afforestation and deforestation on water yields," Journal of Hydrology, vol. 178, no. 1-4, pp. 293-309, 1996.

[32] W. A. Hoffmann and R. B. Jackson, "Vegetation-climate feedbacks in the conversion of tropical savanna to Grassland," Journal of Climate, vol. 13, no. 9, pp. 1593-1602, 2000. 
[33] R. A. Vertessy, F. G. R. Watson, and S. K. O’Sullivan, "Factors determining relations between stand age and catchment water balance in mountain ash forests," Forest Ecology and Management, vol. 143, no. 1-3, pp. 13-26, 2001.

[34] J. D. Stednick, "Monitoring the effects of timber harvest on annual water yield," Journal of Hydrology, vol. 176, no. 1-4, pp. 79-95, 1996.

[35] G. G. Ice and J. D. Stednick, A Century of Forest and Wildland Watershed Lessons, Society of American Foresters, 2004.

[36] C. Raudsepp-Hearne, G. D. Peterson, and E. M. Bennett, "Ecosystem service bundles for analyzing tradeoffs in diverse landscapes," Proceedings of the National Academy of Sciences of the United States of America, vol. 107, no. 11, pp. 5242-5247, 2010.

[37] J. Newcome, A. Provins, H. Johns et al., "The economic, social and ecological value of ecosystem services department for environment, food and rural affairs," 2005, https://www.cbd.int/ doc/case-studies/inc/cs-inc-uk6-en.pdf.

[38] L. Tianhong, L. Wenkai, and Q. Zhenghan, "Variations in ecosystem service value in response to land use changes in Shenzhen," Ecological Economics, vol. 69, no. 7, pp. 1427-1435, 2010.

[39] S. Su, R. Xiao, Z. Jiang, and Y. Zhang, "Characterizing landscape pattern and ecosystem service value changes for urbanization impacts at an eco-regional scale," Applied Geography, vol. 34, no. 2, pp. 295-305, 2012.

[40] R. C. Estoque and Y. Murayama, "Examining the potential impact of land use/cover changes on the ecosystem services of Baguio city, the Philippines: a scenario-based analysis," Applied Geography, vol. 35, no. 1, pp. 316-326, 2012.

[41] W. R. Turner, K. Brandon, T. M. Brooks, R. Costanza, G. A. B. Da Fonseca, and R. Portela, "Global conservation of biodiversity and ecosystem services," BioScience, vol. 57, no. 10, pp. 868-873, 2007.

[42] U. P. Kreuter, H. G. Harris, M. D. Matlock, and R. E. Lacey, "Change in ecosystem service values in the San Antonio area, Texas," Ecological Economics, vol. 39, no. 3, pp. 333-346, 2001.

[43] A. Troy and M. A. Wilson, "Mapping ecosystem services: practical challenges and opportunities in linking GIS and value transfer," Ecological Economics, vol. 60, no. 2, pp. 435-449, 2006.

[44] H. Tallis and S. Polasky, "Mapping and valuing ecosystem services as an approach for conservation and natural-resource management," Annals of the New York Academy of Sciences, vol. 1162 , pp. 265-283, 2009.

[45] E. Nelson, G. Mendoza, J. Regetz et al., "Modeling multiple ecosystem services, biodiversity conservation, commodity production, and tradeoffs at landscape scales," Frontiers in Ecology and the Environment, vol. 7, no. 1, pp. 4-11, 2009.

[46] K. Chopra, Ecosystems and Human Well-Being: Policy Responses: Findings of the Responses Working Group, Island Press, 2005.

[47] U. Nea, "The UK national ecosystem assessment," in Synthesis of the Key Findings, UNEP-WCMC, Cambridge, UK, 2011.

[48] D. Xie, X. Yu, and L. Chunxia, "Study on ecosystem services: progress, limitation and basic paradigm," Acta Phytoecological Sinica, vol. 30, no. 2, article 191, 2006.

[49] Y. Xiao, G. Xie, and K. An, "Economic value of ecosystem services in Mangcuo Lake drainage basin," Chinese Journal of Applied Ecology, vol. 14, no. 5, pp. 676-680, 2003.

[50] K. H. Riitters, J. D. Wickham, R. V. O’Neill et al., "Fragmentation of continental United States forests," Ecosystems, vol. 5, no. 8, pp. 815-822, 2002.
[51] S. Polasky, E. Nelson, D. Pennington, and K. A. Johnson, "The impact of land-use change on ecosystem services, biodiversity and returns to landowners: a case study in the state of Minnesota," Environmental and Resource Economics, vol. 48, no. 2, pp. 219-242, 2011.

[52] B. Fisher, K. Turner, M. Zylstra et al., "Ecosystem services and economic theory: integration for policy-relevant research," Ecological Applications, vol. 18, no. 8, pp. 2050-2067, 2008.

[53] E. Pereira, C. Queiroz, H. M. Pereira, and L. Vicente, "Ecosystem services and human well-being: a participatory study in a mountain community in Portugal," Ecology and Society, vol. 10, no. 2, article 14, 2005.

[54] G. C. Daily, S. Alexander, P. R. Ehrlich et al., Ecosystem Services: Benefits Supplied to Human Societies By Natural Ecosystems, Ecological Society of America, Washington, DC, USA, 1997.

[55] J. D. Floros, R. Newsome, W. Fisher et al., "The importance of food science and technology," Comprehensive Reviews in Food Science and Food Safety, vol. 9, no. 5, pp. 572-599, 2010.

[56] Z. L. Zhu and D. L. Chen, "Nitrogen fertilizer use in Chinacontributions to food production, impacts on the environment and best management strategies," Nutrient Cycling in Agroecosystems, vol. 63, no. 2-3, pp. 117-127, 2002.

[57] G. C. Nelson, E. Bennett, A. A. Berhe et al., "Anthropogenic drivers of ecosystem change: an overview," Ecology and Society, vol. 11, no. 2, article 29, 2006.

[58] C. F. Corvalan, S. Hales, and A. A. J. Mcmichael, Ecosystems and Human Well-Being: Health Synthesis, World Health Organization, Lyon, France, 2005.

[59] C. D. Butler and W. Oluoch-Kosura, "Linking future ecosystem services and future human well-being," Ecology and Society, vol. 11, no. 1, article 30, 2006.

[60] L. E. Caulfield, M. de Onis, M. Blössner, and R. E. Black, "Undernutrition as an underlying cause of child deaths associated with diarrhea, pneumonia, malaria, and measles," The American Journal of Clinical Nutrition, vol. 80, no. 1, pp. 193198, 2004.

[61] W. Aktar, D. Sengupta, and A. Chowdhury, "Impact of pesticides use in agriculture: their benefits and hazards," Interdisciplinary Toxicology, vol. 2, no. 1, pp. 1-12, 2009.

[62] R. N. M. Sehgal, "Deforestation and avian infectious diseases," Journal of Experimental Biology, vol. 213, no. 6, pp. 955-960, 2010.

[63] J. Patz, A. Githeko, J. Mccarty, S. Hussein, U. Confalonieri, and N. de Wet, "Climate change and infectious diseases," in Climate Change and Human Health: Risks and Responses, pp. 103-137, 2003. 

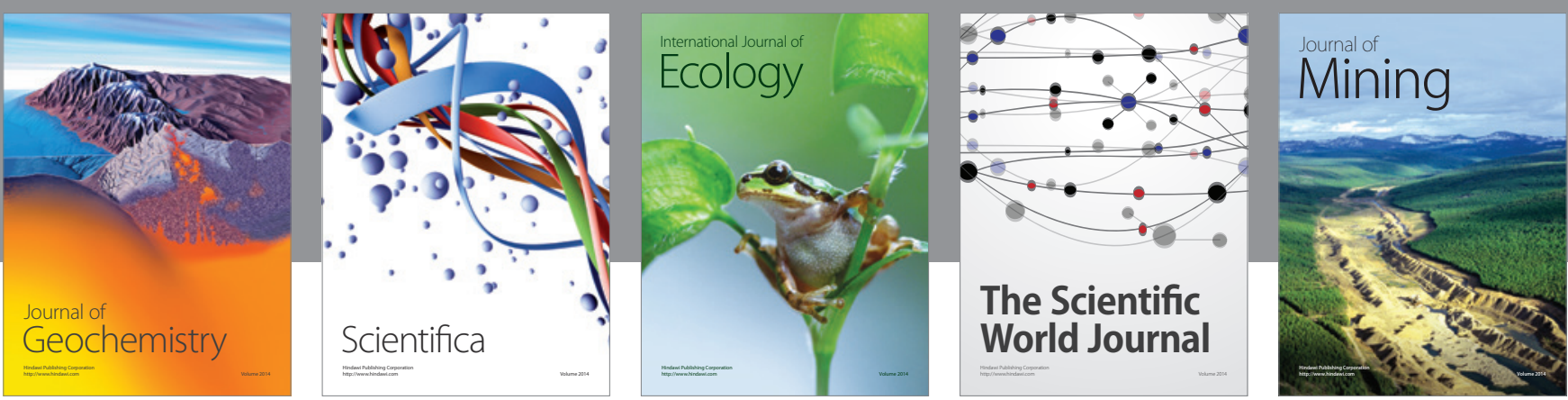

The Scientific World Journal
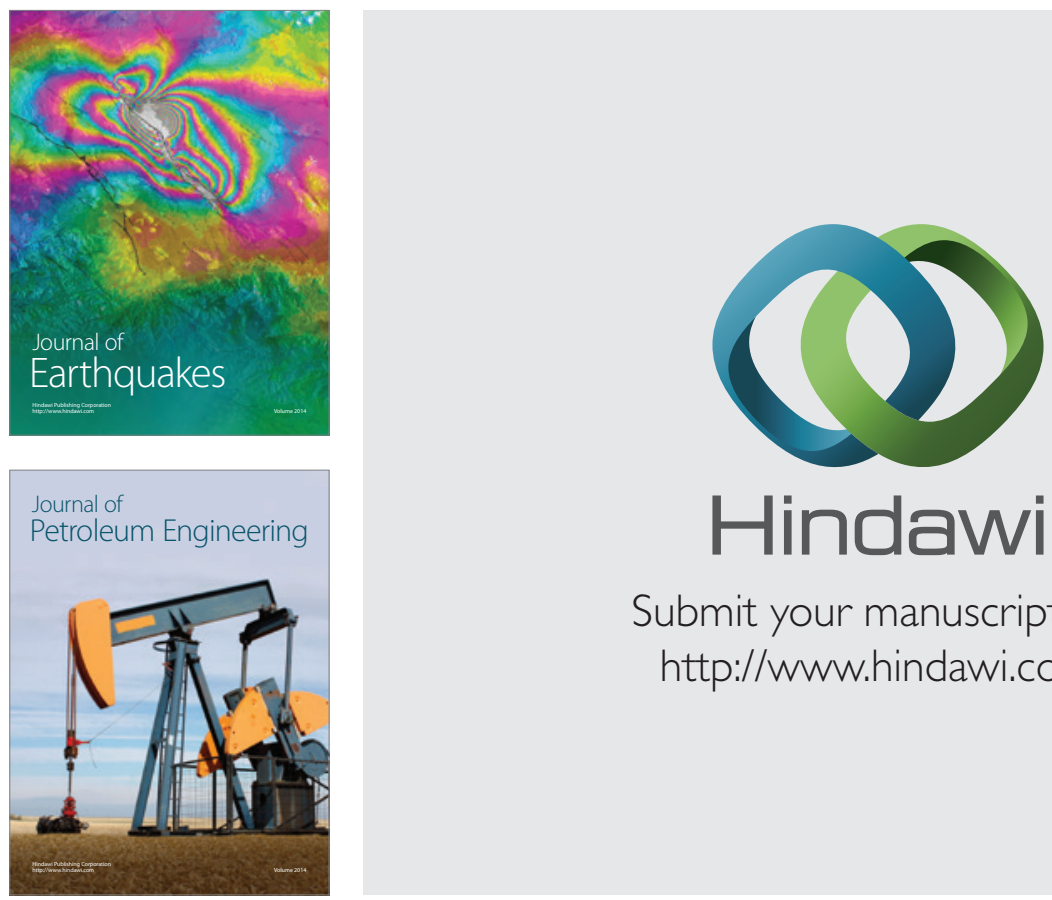

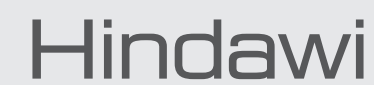

Submit your manuscripts at

http://www.hindawi.com
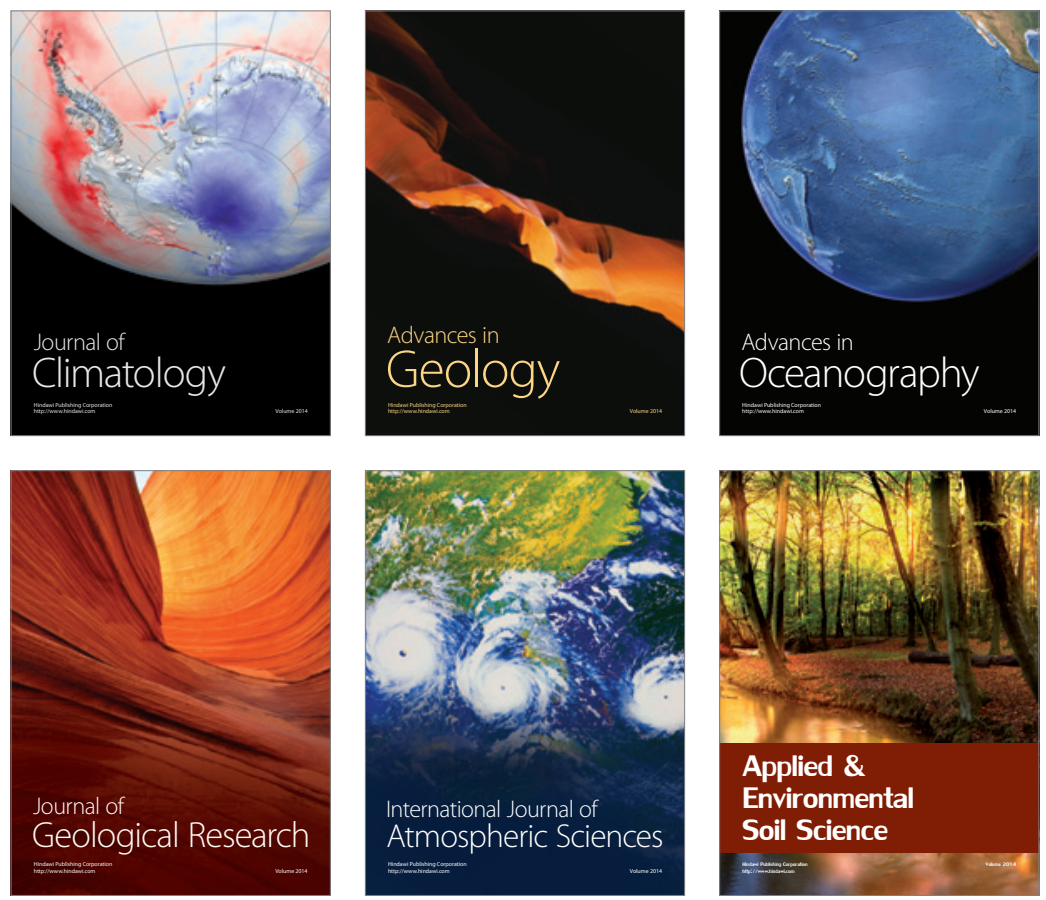
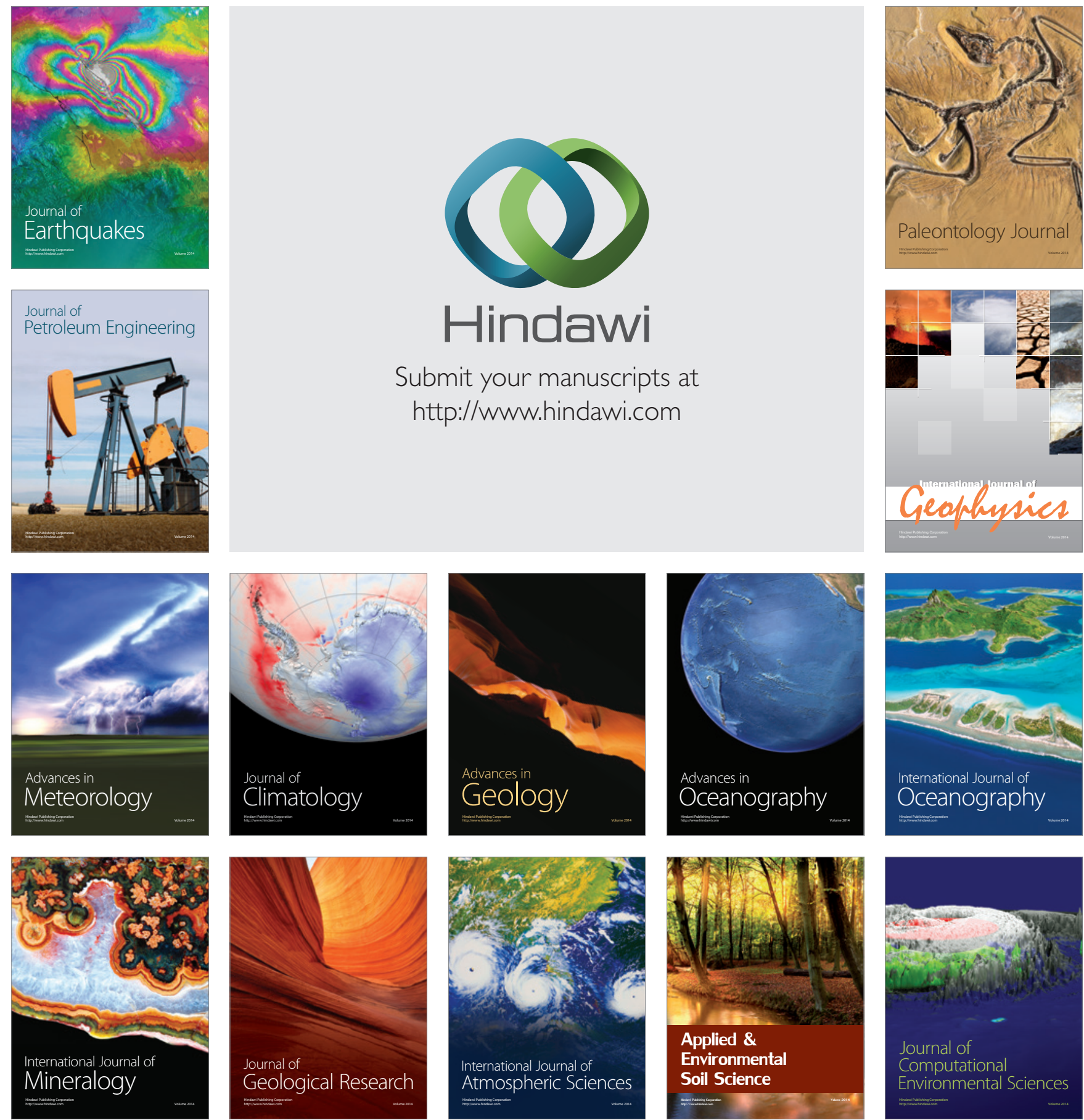